\title{
A crise da razão no ocidente ${ }^{1}$
}

\author{
Hilton Japiassu ${ }^{2}$ \\ Universidade Federal do Rio de Janeiro
}

resumo Ainda é muito freqüente apresentar as atividades científicas como "racionais". Nesse sentido, um fosso praticamente intransponível separaria a racionalidade científica do domínio maldito do "irracional". Numa sociedade como a nossa, dominada pela tecnociência, entregue ao culto do rendimento e à tecnocracia, a preocupação em se garantir o primado do racional é totalmente compreensível. Contrariamente à inteligência, a razão, no entanto, não é um dado natural, mas um conjunto historicamente construído de procedimentos, regras e coerções. Embora seja portadora de um aspecto incontestavelmente lógico, podemos falar de uma história da razão, em estreita ligação com a história do ocidente, vale dizer, com a história da cultura ocidental. Nos últimos tempos, vem se impondo um estilo de pensamento caracterizado por uma profunda desconfiança da "razão" que, por ignorar completamente ser evolutiva, tornou-se profundamente intolerante em relação às paixões, às emoções e aos mistérios. A "razão" se transformou numa racionalidade instrumental prestando culto aos meios em detrimento dos fins. Donde o desencanto com a "razão" e o advento do niilismo. Buscar compreender esse fenômeno que tem sido designado como "crise da razão ocidental" é o objetivo deste artigo.

palavras-chave: razão, racionalidade científica, crise da razão ocidental

abstract It is still very frequent to present scientific activities as "rational". In this sense, a trench that practically cannot be passed through would separate scientific rationality from the damned domain of the "irrational". In a society

\footnotetext{
1 Este artigo foi gentilmente cedido pela Editora Eletrônica (www.editoraeletrônica.net) para publicação impressa.

2 Instituto de Filosofia e Ciências Sociais da Universidade Federal do Rio de Janeiro.
} 
like ours, dominated by techno science, surrendered to the cult of profit and to technocracy, the worry in assuring the primacy of the rational is totally understandable. Contrary to intelligence, reason, however, is not naturally given, but it is a set of historically built procedures, rules and coercions. Although being bearer of an incontestable logical aspect, we can talk about a history of reason, in close relation to the occident history, that is to say, the history of the occidental culture. Lately it has been imposed a style of thought featured by a profound distrust in reason which, by completely ignoring its own evolutive feature, has turned to be profoundly intolerant to passions, emotions and mysteries. Reason has turned into an instrumental rationality, revering the means to the detriment of the ends. Hence the disenchantment with reason and the advent of nihilism. The aim of this paper is to seek to understand this phenomenon that has been named as "crisis of the occidental reason".

key words: reason, scientific rationality, crisis of the occidental reason

Desde Pascal, sabemos que a Razão tem suas razões que a Razão desconhece: as razões do Coração. Mesmo assim, precisamos da Razão para a construção de uma ponte entre as "coisas" do coração e as "coisas" da razão. Precisamos também dela para demonstrar que a Razão não existe, que possui limites, não é onipotente e pode delirar. Se não podemos escapar da Razão, compete ao filósofo definir as regras de seu bom uso. Contrariamente à inteligência, a Razão não é um dado natural, mas um conjunto historicamente construído de procedimentos, regras e coerções. Corresponde a uma vontade de possuir uma visão coerente dos fenômenos e do mundo. Embora seja portadora de um aspeto incontestavelmente lógico, podemos falar de uma história da razão, em estreita ligação com a história do Ocidente, vale dizer, com a história da cultura ocidental que se funda em duas raízes: a greco-romana e a judaico-cristã.

Existiria apenas uma razão, aquilo que os ocidentais chamam de "a" Razão? Ou poderíamos falar de razões no plural? Claro que só existe uma razão, caso contrário não teriam validade as leis científicas. Mas ela se exprime em formas diversas. O singular da 
Razão não é incompatível com o plural das racionalidades, vale dizer, com essas diversas formas de nosso espírito criar estruturas lógicas para aplicá-las ao mundo real e com ele dialogar: embora não pretenda esgotar a totalidade do real num sistema lógico e coerente (racionalização), a racionalidade tem a pretensão de dialogar com o que lhe resiste, pois "há mais coisa no mundo que em nossa filosofia". $\mathrm{O}$ universo é muito mais rico do que podem concebê-lo nossas estruturas lógicas e racionais. O que é particular ao Ocidente é esta forma de racionalidade denominada racionalismo, isto é, a crença segundo a qual todo objeto só pode ser pensado e resolvido por um bom uso da Razão. Em outras palavras, o racionalismo tanto pode ser:

- uma visão de mundo afirmando o perfeito acordo entre o racional (coerência) e a realidade do universo (excluindo todo irracional, todas as emoções, os sentimentos, as necessidades, as paixões: a subjetividade)

-quanto uma ética afirmando que as ações humanas e as sociedades podem e devem ser racionais em seu princípio, em sua conduta e em sua finalidade. Em suma, o racionalismo consiste no fato de se erigir a Razão (sob sua variante ocidental de razão científica) em sistema absoluto promovendo um cientificismo para o qual "fora da ciência não há salvação" e que a Ciência constitui o único caminho susceptível de conduzir-nos à Verdade.

A grande tese do racionalismo (como doutrina filosófica) consiste em afirmar: nada existe que não tenha sua razão de ser, de tal forma que, de direito, nada existe que não seja inteligível. Leibniz a formula assim: "nada jamais acontece sem que haja uma causa determinante, isto é, algo que possa servir para dar razão a priori por que isto é existente antes que não existente, e por que isto é assim antes que de qualquer outro modo". Este princípio a priori possui um caráter ontológico: aplica-se mesmo quando nos são desconhecidas as razões determinantes. Por isso, permite-nos responder à questão suprema: por que há algo e não antes o nada? Ao fazer intervir um ser necessário e primeiro, essa argumentação aparece como circular: sem o princípio de 
razão, "jamais poderemos provar a existência de Deus"; sem Deus, não poderemos justificar "por que as coisas andam assim e não de outra maneira". Portanto, para evitar uma postura dogmática racionalmente injustificada, o racionalismo prefere apresentar-se como uma atitude intelectual consistindo em elucidar razões válidas para se admitir como verdadeiras ou verossimilhantes e se rejeitar como falsas ou absurdas todas as hipóteses podendo ser forjadas a propósito do que acontece na natureza.

Se por Razão entendemos um método de conhecimento fundado no cálculo e na lógica para resolver problemas postos pelo espírito humano em função dos dados que caracterizam uma situação ou determinado fenômeno; por racionalidade uma adequação estabelecida entre uma coerência lógica (descritiva ou explicativa) e determinada realidade empírica; e por racionalização a construção de uma visão coerente e totalizante do universo com base nos dados parciais ou em um princípio único, perceberemos que a aventura da Razão Ocidental produziu, a partir do século XVII, um robusto racionalismo, várias formas de racionalidades e de racionalizações. É inegável que, por oposição às explicações mitológicas e às revelações religiosas, o desenvolvimento da ciência ocidental constitui uma busca constante de racionalidade: impõe-se rompendo com a racionalização aristotélico-medieval e afirmando o primado da experiência sobre a coerência. E progride na dupla tensão entre racionalismo e empirismo: o primado da experiência rompendo com as teorias racionalizadoras, mas a cada nova desracionalização se sucedendo uma nova tentativa de re-racionalização.

No final do século XVIII, os êxitos da física permitem se conceber um universo determinista totalmente inteligível ao cálculo. Um demônio ideal, imaginado por Laplace, poderia deduzir todo estado presente ou futuro deste Universo. Doravante, o racionalismo dispõe de uma visão do mundo comportando a identidade do real, do racional e do calculável. Hegel proclama: "todo real é racional e todo racional é real". Desta visão de mundo são eliminadas toda desordem e toda subjetividade. A Razão se converte no grande mito unificador do Saber, da Ética e da Política. Todos deveríamos viver segundo a 
Razão, isto é, repudiar os apelos da fé e da paixão. E a vida segundo a Razão passa a ser conforme aos princípios utilitários da economia liberal-burguesa: segundo a ordem e a harmonia. Trata-se de uma Razão liberal, pois o homem é suposto naturalmente razoável. Donde se poder optar, não só pelo déspota esclarecido, mas pela democracia e a liberdade que permitirão à Razão coletiva exprimir-se e à Razão individual desabrochar-se.

O racionalismo das Luzes ainda é bastante humanista: associa sincreticamente o respeito e o culto do homem (ser livre, sujeito do universo) e a ideologia de um mundo totalmente racional. Por isso, apresenta-se como uma ideologia da emancipação e do progresso. Em sua luta permanente contra o mito, as superstições, os obscurantismos e as religiões, promovem um saber empiricamente fundado e experimentalmente verificável: funda-se ao mesmo tempo no consenso e no conflito; ademais, ergue-se sobre quatro pilastras independentes e interdependentes: a racionalidade, o empirismo, a imaginação e a verificação. $O$ princípio de seu universalismo, junto com a exaltação da idéia de homem, constitui o fermento da emancipação dos escravos e oprimidos, da igualdade dos direitos dos cidadãos e dos povos. É a desconfiança no homo sapiens, homem sujeito-racional (esvaziado de toda afetividade e de toda irracionalidade) que permite se universalizar o princípio da liberdade. Claro que esses princípios universais ainda são abstratos, constituindo-se sobre a ignorância e o ocultamento das diferenças culturais e individuais. Mas conduzem, inconscientemente, à promoção de determinada homogeneização e à quebra de inúmeras diferenças (o diferente era considerado inferior). Contudo, esse racionalismo só permanece emancipatório enquanto se mantém vinculado ao humanismo (unindo amor da humanidade, paixão pela justiça, pela liberdade, pela igualdade). Uma vez abandonadas as idéias humanistas, a racionalização começa a devorar a Razão. E os homens deixam de ser concebidos como indivíduos livres ou sujeitos. Passam a obedecer à aparente racionalidade do Estado, da Burocracia e do Mercado.

Se levarmos em conta que a atitude científica sempre desempenhou um papel importante no diálogo entre o real e o 
possível, perceberemos que o século XVII teve a sabedoria de proclamar que a Razão constitui, doravante, um instrumento necessário para tratar os negócios humanos e sociais. O século das Luzes cometeu a loucura de pensar que a Razão não somente é necessária, mas suficiente. Será que não estaríamos hoje incorrendo numa loucura muito maior quando, a pretexto de reconhecerem a insuficiência da Razão, muitos já estão afirmando que ela se torna desnecessária? O processo de autodestruição da Razão é bastante recente. Começou quando se converteu em "razão instrumental" e passou a impor-se como concepção unidimensional, vale dizer, a conceber-se e apresentar-se como racionalização ditatorial e totalitária. No dizer de Adorno, "a razão se comporta em relação às coisas como um ditador em relação aos homens: ele os conhece na medida em que pode manipulá-los". Basta que os homens sejam considerados coisas para que se tornem manipuláveis, submetidos à ditadura racionalizada moderna (que encontra seu apogeu nos campos de concentração).

A Razão possui, oculta em seu cerne, uma irracionalidade. Quando esta se manifesta, a Razão se enlouquece e gera os totalitarismos. Quando há uma derrocada do humanismo e da virtude crítica, desencadeia-se uma força implacável de ordem e homogeneização. A Razão começa a se enlouquecer quando se torna ao mesmo tempo puro instrumento do poder (e dos poderes) e da ordem. Quando se converte no fim do poder e dos poderes, quer dizer, quando a racionalização, sem deixar de constituir um instrumento dos processos bárbaros de dominação, passa a instaurar e a justificar uma ordem racionalizadora na qual tudo o que a perturba deve ser considerado como criminoso, demente ou subversivo. Porque o discurso do Poder é claro: "ou eu estou certo, ou você está errado"; "se der cara eu ganho, se der coroa você perde". Assim, nessa lógica, como salienta Edgar Morin, "produz-se não somente uma burocracia para a sociedade, mas uma sociedade para esta burocracia; não somente se produz uma tecnocracia para o povo, mas se constrói um povo para esta tecnocracia; não somente se produz um objeto para o sujeito, mas se produz um sujeito para o objeto". E a loucura se instala quando 
esses processos bárbaros de racionalização irracional se convertem em processos que conduzem à morte. Por isso, devemos lutar contra toda deificação da Razão. Mas devemos fazer dela nosso mais confiável instrumento de conhecimento, contanto que a tornemos crítica e autocrítica: tanto delira a incoerência absoluta quanto a coerência total.

Sabemos que o modelo galileano de Ciência sempre pôs de lado as qualidades sensíveis do mundo. Para conhecermos o verdadeiro ser do universo, precisamos abandonar todas as nossas sensações e impressões, todos os nossos desejos e afetos, numa palavra, tudo o que é subjetivo. Porque o universo é construído apenas de corpos materiais extensos, podendo existir sem que lhe atribuamos nenhuma qualidade e ser conhecido apenas pelo poder de uma Razão apta a dominá-lo, a tornar-nos seus "mestres e possuidores" (Descartes). A realidade das coisas fica reduzida às suas determinações ideais. É abandonando inteiramente o caráter sensível deste mundo onde vivemos, o caráter que faz dele um mundo humano e da vida, que podemos propriamente conhecê-lo, quer dizer, dele nos apropriar para sobre ele exercer um poder. Instaura-se o "paradigma de simplificação" caracterizado pelos princípios de disjunção, redução e abstração. Ao separar completamente o Sujeito pensante e o Objeto extenso (filosofia e ciência), afirmando como princípio de verdade as idéias "claras e distintas", Descartes instaura o paradigma disjuntivo que vai controlar o pensamento ocidental desde o século XVII até bem recentemente, quando se começa a perceber suas conseqüências nocivas.

Mas não estaria esse recalcado voltando à tona? Não estaria querendo manifestar-se essas determinações invisíveis? Não estamos assistindo hoje a uma onda de crítica à raciomania que se instaurou com a revolução científica moderna? Não corre essa crítica o risco de converter-se numa verdadeira misologia (ódio ou hostilidade à Razão: misologos - misos: ódio, aversão; logos: discurso, ciência, razão)? O ponto de estrangulamento dessa aversão se manifesta no jogo da Ciência e de seu Outro, vale dizer, do Saber e do inconscientemente sabido. Este "Outro" é o Oculto da própria Ciência, aquilo que não está revelado ou que por ela foi sistematicamente proscrito, reprimido 
ou recalcado. No fundo, trata-se da subjetividade, freqüentemente identificada com o irracional e com o passional.

Diria que a chamada "pós-modernidade" aparece como uma espécie de Renascimento dos ideais banidos e cassados por nossa modernidade racionalizadora. Esta modernidade teria terminado a partir do momento em que não podemos mais falar da história como algo de unitário e quando morre o mito do Progresso. É a emergência desses ideais que seria responsável por toda uma onda de comportamentos e de atitudes irracionais e desencantados em relação à política e pelo crescimento do ceticismo face aos valores fundamentais da modernidade. Estaríamos dando Adeus à modernidade, à Razão (Feyerabend)? Quem acredita ainda que "todo real é racional e que todo real é racional"(Hegel)? Que esperança podemos depositar no projeto da Razão emancipada, quando sabemos que se orientou para a instrumentalidade e a simples produtividade? Que projeto de felicidade pessoal pode proporcionar-nos um mundo crescentemente racionalizado, calculador e burocratizado, que coloca no centro de tudo o econômico, entendido apenas como o financeiro submetido ao jogo cego do mercado? Como pode o homem ser feliz no interior da lógica do sistema, onde só tem valor o que funciona segundo previsões, onde seus desejos, suas paixões, necessidades e aspirações passam a ser racionalmente administrados e manipulados pela lógica da eficácia econômica que o reduz ao papel de simples consumidor?

Neste mundo desencantado, dessacralizado, dominado pelo Instrumental e pelo Funcional, onde o homem perdeu toda concepção unitária e de totalidade, inteiramente concebido segundo uma visão objetivista, onde irá ele encontrar as melhores razões ou motivos para viver e respostas para suas inquietações existenciais? Neste mundo dominado pelo monoteísmo do mercado, onde o indivíduo livre e soberano é reduzido a uma marionete realizando espasmodicamente os gestos que lhe impõe o campo sociocultural (ganhar dinheiro, consumir e "gozar"), quem irá despertá-lo do "sono dogmático" da apatia, da indiferença, do cinismo, do ceticismo e do cansaço utópico-político? Não lhe restaria apenas o destino, esta espécie de divindade 
identificada com um poder mais ou menos personificado, governando tudo o que existe no universo e determinando uma vez por todas e irreversivelmente todo o curso geral dos acontecimentos e o curso da história humana? Existir, para ele, não significaria apenas ser pressionado pela urgência do tempo, num mundo onde não sabe mais quem é, o que pode pensar e fazer, embora se veja obrigado a inventar algo para fazer e sobre o que pensar a fim de dar-se a ilusão de ainda ser livre?

Nos últimos tempos, vem se impondo um estilo de pensamento caracterizado por uma profunda desconfiança da Razão que, por ignorar completamente ser evolutiva, tornou-se profundamente intolerante em relação às paixões, às emoções e aos mistérios. A Razão Ilustrada não gerou sociedades tão justas, livres e fraternas como prometera. Nem todas as suas promessas foram cumpridas. Sua racionalidade tecnocientífica não transformou os homens e seres mais humanos. Pelo contrário, converteu-os em burgueses interessados muito mais num progresso desenvolvimentista voltado para 0 produtivismo sem freios e para um consumismo desvairado. A Razão se transformou numa racionalidade instrumental prestando culto aos meios em detrimento dos fins. Donde o desencanto com a Razão e o advento do niilismo pregando a ruína dos valores consagrados da civilização ocidental e exaltando o desabrochamento dos instintos fundamentais da vida e da vontade de poder, "para além do bem e do mal".

Se a Razão não pode mais nos fornecer um "porto seguro" capaz de proteger-nos contra as intempéries das ideologias, dos dogmatismos e das manifestações do irracional (fundamentalismos, racismos, integrismos, etc.), somos obrigados a viver num mundo sem horizonte fixo e sem fundamento. Vivemos mais ou menos à deriva. Encontramo-nos numa situação semelhante à dos renascentistas (e à da crise grega, socrática): tendo destruído a física, a metafísica e a ontologia aristotélicas (a grande síntese racionalizadora), ficaram sem possibilidade de decidir se alguma coisa é ou não possível. E passaram a acreditar no "tudo é possível". Da mesma forma, estamos assistindo ao desmoronamento de uma racionalidade científica fundada numa 
Objetividade que expulsou do mundo e recalcou suas qualidades sensíveis e tudo o que diz respeito à subjetividade e à vida. Contra as ameaças de um pensamento uniformizador e homogeneizador, fundado na dominação da racionalidade tecnocientífica, novos valores são buscados: a multiplicidade dos pensamentos, a pluralidade das visões de mundo, a diversidade dos modos de viver, pensar e agir.

$\mathrm{O}$ que se pretende é construir um mundo onde seja possível a expansão de todas as criatividades e onde possam conviver todas as pluralidades. Busca-se valorizar uma nova "episteme": da indeterminação, da descontinuidade e do pluralismo, não aceitando mais nenhum tipo de dogmatismo, pois é gerador de violência. No fundo, a violência e o assassinato cometidos por motivos individuais desempenham apenas um papel insignificante no curso da História. $\mathrm{O}$ que matou e mata milhões é a conviç̧ão de possuir a verdade e a vontade de impô-la aos outros. O homem ocidental matou em nome de Deus, em nome de princípios nazistas, stalinistas e até científicos (racismo). Sempre se matou em massa para se defender princípios ideológicos ou religiosos. A este respeito, diz F. Jacob: "Não é somente o interesse que leva os homens a se matarem. Também é o dogmatismo. Nada é tão perigoso quanto a certeza de ter razão. Nada causa tanta destruição quanto a obsessão de uma verdade considerada como absoluta. Todos os crimes da História são conseqüência de algum fanatismo. Todos os massacres foram realizados por virtude: em nome da religião verdadeira, do racionalismo legítimo, da política idônea, da ideologia justa; em suma, em nome do combater contra a verdade do outro, do combate contra Satã".

Por outro lado, o homem de hoje tende a recusar os megarrelatos, as grandes sínteses filosóficas, políticas, ideológicas e religiosas que tanta segurança lhe forneceram num passado ainda recente. Esses grandes relatos nos propunham um visão integrada e coerente do mundo (cosmovisão), nos forneciam uma explicação total para todos os aspetos da realidade, faziam-nos aceitar as normas regulando as condutas e comportamentos, davam coesão aos grupos humanos e legitimavam os sistemas de valores. Freqüentemente confundidos com visões objetivas da realidade, tinham a vantagem de 
fornecer um sentido, uma orientação e um guia para os indivíduos. Chegavam mesmo a propor-lhes uma "salvação". Sem nos esquecermos de que o surgimento dos meios de comunicação de massa foi determinante para o processo de dissolução desses pontos de vista centrais ou grandes narrativas. Contra esses universalismos disciplinadores, insurgem-se os que defendem contextos locais, a heterogeneidade das formas de vida, as particularidades dos modos de ser, agir e pensar, uma ética das circunstâncias e uma autonomia moral em relação às normas universais. $\mathrm{O}$ grande perigo é o de tal situação favorecer "um ingênuo anarquismo liberal" (Habermas), promover uma profunda aversão à política e conduzir os indivíduos a uma enorme apatia social, mesclada com um pluralismo neoliberal típico das sociedades de consumo. Sem falarmos no fato de a mídia ter-se convertido no elemento decisivo de uma explosão e multiplicação generalizada de visões de mundo fragmentadas.

Estaríamos hoje entregues (como reconhece J. Baudrillard) ao esteticismo do presente e assistindo a uma esteticização geral da vida? Qual a conseqüência da perda, não somente de fundamento da Razão e de sentido da História, mas dos princípios gerais (para a ciência e a moral)? Diria que vivemos num mundo mutante onde a Razão deixa de ser um meio objetivante para converter-se num instrumento fruitivo. $\mathrm{O}$ que importa é vivermos a vida e usufruirmos de tudo o que ela pode fornecer-nos de vantagens individuais. Este anarquismo liberal se transforma numa profunda aversão à política, levando os indivíduos a uma enorme apatia social, mesclada com um pluralismo neoliberal típico das sociedades de consumo. Em síntese;

-não acreditamos mais numa Razão fundadora capaz de nos proporcionar uma base sólida, permitindo-nos formular uma visão coerente e totalizante da realidade, do homem, de seus comportamentos e valores;

-não acreditamos mais nos megarrelatos capazes de fornecer um sentido à História e de legitimar os projetos políticos, sociais e econômicos; porque são geradores de coerções, uniformidades e totalitarismos; 
-não acreditamos mais no projeto da modernidade enquanto estilo de pensamento e de vida; projeto desenvolvimentista, competitivista e funcionalista. Porque não somente estamos buscando uma nova concepção da Razão e uma racionalidade pluralista, mas uma compreensão da vida humana não objetivante, não instrumental e não logicista; e tudo isso procurando descobrir princípios políticos e éticos que nos impeçam de cair na atual onda de neo-conservadorismo que nos domina.

No plano do Absoluto, o que representam o atual desencanto com a Razão e a negação de todo fundamento e de toda certeza? Representam a aceitação mesma da "morte de Deus". Claro que praticamente não existe mais quem reivindique um ateísmo militante. $\mathrm{O}$ que se busca é uma forma de niilismo positivo afirmando-se pela exaltação de novos valores da vida. O que não deixa de ser importante não somente para se purificar o conceito mesmo de Deus, mas para se elaborar uma crítica dos ídolos. De um modo geral, o Deus do homem atual não é mais o "Deus dos filósofos e dos sábios" e, muito menos, um Deus pessoal. Trata-se de uma divindade que se encontra muito além de nossas representações e de nossos conceitos. Na prática, confunde-se com uma espécie de "Absoluto" mistérico, energético ou cósmico, manifestando-se nas experiências individuais do "conhecimento" místico, esotérico, transcendental, oculto ou religioso ("autoconhecimento"). Exalta-se certo maravilhosismo e certo experimentalismo. A crítica e a negação da Razão servem de pretexto para se ter acesso ao "mistério", ao "profundo". Tudo se passa como se só tivesse valor o "conheça-te a ti mesmo" socrático. Evidentemente, não se cai num ceticismo radical ou negativo. O que se procura é relativizar a Razão, abrir-se a outras vias de acesso ao mistério, menos objetivantes e preferencialmente "meditantes". Ao se tomar consciência de que a Razão não esgota a realidade, nega-se o reducionismo tecnoprodutivista e funcional que, demasiadamente preocupado com a superficialidade mensurável do real, torna-se inteiramente cego às suas dimensões profundas e ocultas. Qual o risco 
de se conferir o primado à experiência? Não somente é o de cairmos num consumismo frívolo de sensações, mas de aceitarmos uma "religiosidade" à la carte, o "religioso" se convertendo num esteticismo gustativo das realidades mistéricas, energéticas, ocultas ou esotéricas, implicando a aceitação de certa idolatria ou de certo panteísmo gnosticista.

O proclamado "fim da história" nada mais é do que a derrocada da "filosofia da história" e a conseqüente emancipação da multiplicidade dos horizontes de sentido. Contudo, é na perda mesma de sentido que precisamos buscar um sentido para a História: a multiplicidade dos horizontes de sentido, longe de constituir uma tragédia, revela-se uma fonte rica de significações e conseqüências inexploráveis. O grande responsável por nossa dissolução na pluralidade de sentidos e pela liquidação da história é a mídia. Vivemos hoje sem quadro de referências. Os fatos e os acontecimentos são-nos apresentados ou mostrados de modo bastante fragmentado. São observados de todos os ângulos, mas carecem de uma referência a uma totalidade que lhes dê sentido. De todos os acontecimentos, só vemos detalhes. Consumimos milhões de notícias descartáveis sem reflexão. Os efeitos especiais e secundários nos escondem o fundamental. Não sabemos mais distinguir o importante do trivial. A informática, as redes de comunicação e a mídia convertem-se num grande acelerador de partículas impedindo-nos de perceber a órbita referencial das coisas. E com a perda do horizonte histórico, perdemos também o sentido da história, passando a viver apenas na imediatez dos momentos.

Nosso grande desafio consiste em elaborarmos um projeto pessoal de vida no qual cada um de nós tenha reais condições de afirmar-se como indivíduo autônomo, não se fechando em sua vida privada (mas sendo capaz de abrir-se à ação), não se cansando de lutar pela liberdade nem se tornando cínico em relação à política. Porque não devemos fazer concessão ao Saber. Seria fazer concessão à Liberdade. E fazer concessão à liberdade é agir conforme o desejo dos outros. Se assim procedermos, nos alienamos, obedecendo à sua lei. E assumimos a servidão que, por ser voluntária, provoca em nós uma 
dupla atitude: de ignorância e de canalhice. Não podemos aceitar que ninguém se aproveite de sua posição de Saber para nos impor algo capaz de impedir a manifestação de nosso desejo ou de nossa liberdade, conseqüentemente, de nosso saber. Nem pedagogias, nem terapêuticas nem governos: essas práticas participam da escolha por um outro. Precisamos questionar essas técnicas que bloqueiam os desejos dos seres humanos: de reeducação, readaptação, reintegração, ressocialização, etc. Têm por objetivo nossa normalização (enquadramento nas normas). Ora, a função de nossos saberes sobre o homem e a sociedade é a de inventar as normas, não de impô-las. Não há canalhice em inventá-las e fazê-las respeitar, em difundi-las e ensiná-las, mas quando pretendemos fazê-las passar por aquilo que não são: "leis da natureza", não da sociedade.

Ninguém mais duvida que a racionalidade constitui a marca distintiva de nossas sociedades modernas. Também é incontestável que possui um valor eminente: é portadora de um poder eficaz por meio das ciências e das técnicas, gozando de prestígio colocando-a praticamente à parte e acima de tudo. O poeta Neruda reconhece: "É a razão, base da justiça, que deve governar o mundo". Nada mais instrutivo do que o modo como hoje a sociologia se apresenta: a garantidora da hegemonia sobre todos os aspetos da vida em comum. No contexto das ciências sociais, é ela que, "em seus conceitos fundamentais, melhor se vincula à problemática da racionalidade" (Habermas). Dizer que toma de empréstimo sua lógica da economia significa o mesmo que dizer que faz da economia o princípio da realidade. Neste caso, as relações entre os homens possuem um valor objetivo enquanto são concebidas em função do interesse e do cálculo dos meios e dos fins. Para além, estaríamos no domínio dos fatores psíquicos, dos desejos e das idéias, vale dizer, dos valores.

Donde a importância de uma atitude crítica. Porque vivemos num mundo onde assistimos ao desaparecimento do sentido e das significações e se impõe quase sem contestação a religião do mercado. Só os "pagãos" ou "hereges" ainda contestam essa divindade. Só os "não-modernos" não conseguem entender que "cultura" é o que se vende. O grande valor que se impõe é o dinheiro. 
A máxima do indivíduo privatizado é: "cada um por si e Deus por ninguém". Se não devemos aceitar esse projeto, é porque não acreditamos que essa gigantesca corrente sócio-histórica constitua uma fatalidade fazendo com que tudo se torne insignificante e que só prestemos culto ao efêmero. Se perdermos de vista nosso projeto de autonomia individual e coletiva, se abandonarmos nossa capacidade crítica de resistência e deixarmos de lutar pela emancipação (intelectual, espiritual e afetiva) do ser humano, ficaremos entregues a esse projeto de dominação demencial do novo capitalismo assumindo a fisionomia de um verdadeiro totalitarismo. Porque, quando uma sociedade perde sua capacidade de contestação interna e de indignação, de questionar suas instituições e suas próprias idéias; quando deixa de ser aberta e passa a admitir uma espécie de dogma último, estamos diante de uma forma de pensamento único e homogeneizador, por conseguinte, totalitário.

Com a emergência dos totalitarismos, o desmoronamento das ideologias de esquerda e o declínio da mitologia do Progresso, vivemos um momento histórico caracterizado pela evanescência dos conflitos social, político e ideológico. Nosso mundo pode ser caracterizado por uma tríplice recusa:

- da visão global da História como progresso ou emancipação, conduzindo os indivíduos a adotarem uma atitude de profundo agnosticismo político;

-da idéia de uma razão uniforme e universal, levando os indivíduos a não saberem mais se devem ou não pensar ou a acharem que se equivalem todos os modos de pensar;

- da diferenciação estrita das esferas culturais (arte e filosofia, por exemplo), levando os indivíduos a acreditarem que podem ser fundidas na base de um princípio único de racionalidade ou de funcionalidade. 